\title{
Eduardo de Salterain y Herrera, como Novelista
}

N ACIO Eduardo de Salterain y Herrera, hijo de Joaquín de Salterain y Manuela de Herrera, el 12 de septiembre de 1892 en Montevideo, Uruguay. Hizo sus estudios de Filosofía y Letras en la Universidad de Montevideo e inició su carrera docente en 1917, como Profesor de Literatura del Liceo de Enseñanza Secundaria de Canelones (Uruguay), dictando además momentáneamente las clases de Filosofía y de Historia.

En 1926, obtuvo por concurso la cátedra de Literatura del Instituto Normal de Montevideo, nombrándosele a poco como Profesor del Liceo Nocturno, en la Sección Femenina y en el Liceo No 4 Zorrilla de San Martín.

En 1931, fué Director de la revista Estudios de la Asociación de Profesores de Enseñanza Secundaria. En 1934 desempeñó la Presidencia de la Comisión Directiva de la misma corporación. Instalado el II Congreso Nacional de Profesores de la Enseñanza Media, en Piriápolis, como punto inicial de la reforma de la educación secundaria, fué elegido por el Profesorado para presidirlo. En 1935 fué reelegido para la Presidencia de la Asociación de Profesores.

En los años de 1925 y 1930, realizó diversos viajes de observación y estudio por Europa, Asia y Africa, que dieron riqueza a su espíritu y motivos para varias de sus publicaciones y conferencias. Durante su permanencia en Europa, particularmente en Francia, visitó y estudió los mejores cursos en los grandes liceos Pasteur (Nevilly) y Buffon (Vaugirard). 
En las vacaciones de 1934, invitado por la Ciudad de Lima, realizó un viaje al Perú y a su regreso visitó a Chile y sus Institutos de Educación.

En 1936, fué elegido por el Profesorado para integrar el Consejo Nacional de la Enseñanza Secundaria, organismo autónomo que rige la educación media del Uruguay. El Consejo le designó Presidente y Director General, cargo que desempeña en la actualidad. En este carácter, el Ministerio de Instrucción Pública le nombró en 1937 Presidente de la Comisión Organizadora de los Cursos Suramericanos de Vacaciones, que funcionó en Montevideo en enero de 1938. En el mismo año dictó en Río de Janeiro conferencias de arte y de educación, como miembro de la delegación intelectual uruguaya.

Fué miembro fundador del Instituto de Estudios Superiores, Profesor del mismo y Director de su Sección de Publicaciones; también lo fué de los "Amigos del Arte". Ha publicado las siguientes obras literarias y pedagógicas: Los comentarios (crítica), Perspectivas (idem), Ansiedad, La casa grande y Fuga (cuentos y novelas), Goethe (conferencias), Perfil de viaje (Oriente y Occidente), y La clase (dos volúmenes sobre la enseñanza de la literatura y de la educación artística).

Es interesante notar que la menos popular de estas obras es Fuga, la preferida del autor; sin embargo, esto no le extraña a Salterain. Fuga es una novela analítica presentada en forma de una serie de recuerdos. En ella, la acción está ausente, con excepción de los conflictos íntimos producidos por la turbulencia del alma de los personajes. Salterain escudriña profundamente la fatalidad y la futilidad de las pasiones humanas; analiza con simpatía y comprensión los problemas que resultan de las relaciones entre los mortales y no ofrece para ellos ninguna fácil solución. Fuga puede dividirse en dos partes. En la primera, Alvaro sale de Montevideo para Punta del Este, balneario que el autor describe del modo siguiente:

¿Distracción? ¿Reposo? ¿Ejercicio? Todos los balnearios son un balneario, en que la gente descansa fatigándose. Sosiego prometido que se transforma en bullicio. Libros que no se leen. Noches marchitas. Días que se suceden febrilmente, luna tras luna, sol tras sol en el horizonte, empujando las horas en un vértigo inusitado, más violento que el trajín de la vida ciudadana. La gente va donde la gen- 
te y las auras se renuevan transportando afanes comunes de un grupo a otro grupo, de un sueño a otro. Es un concierto de voluntades uniformes, disciplinadas, porque todos sin previo acuerdo de solidaridad, llevan el mismo destino. Se presienten, se integran y obran de consuno, como el fenómeno del interés social. Por una rara excepción se producen disonancias, pero tan leves que parecen notas perdidas: es uno que vaga errante, otro que escribe o pinta. Pero tarde o temprano, en su ímpetu avasallador, la vorágine puede incorporar el curso de la comunidad, estas corrientes de livianos caudales y rumores apagados.

Allí era excepción la conducta de Alvaro, como indica lo siguiente:

Alvaro desde que llegó se había sustraído al ambiente, no con malhumorados gestos de incomprensión, ni con propósitos de singularizarse, pero sí con el hondo deseo, enervante, casi, de desenvolver su estado de ánimo. Buscaba una inmersión profunda en sí mismo y por ello necesitaba aislarse, complaciéndose en la dolorosa exaltación de su espíritu.

Y piensa.

Y escribe en el aislamiento, sintiendo helarse las médulas, $y$ ar der las sienes, como si temblaran todos los estupores del mundo.

En su Diario escribe sus reflexiones acerca de Inés y sus amores y las razones de su separación. Después de unos meses termina. sus anotaciones con la observación sigtuiente: existe.

Yo soy el hombre que tiene la llave de una puerta que no

\section{Ý por eso}

No escribió más.

La pluma quedó quieta para no saltar las esquirlas del verbo, de la idea y el sentimiento, en fuerza de palanca. Descansó y con ella el alma.

La explicación de esta pérdida de interés en el Diario se encuentra en la simpatía que le daba Nina, amiga de Inés. Al volver a Montevideo, Nina lleva el Diario de Alvaro a Inés. Alvaro y Nina 
sostienen correspondencia epistolar, pero el lector no tiene la oportunidad de leer más que las cartas de la señorita. Un mutuo interés parece fortalecerse entre Alvaro y Nina, pero de repente ésta deja de recibir cartas. Después de varios esfuerzos inútiles por conseguir una contestación:

Ella no escribió más. Tampoco él...

Sin embargo, no se casaron...

Se dijera vulgarmente, que él no hacía frente al mundo, en el panorama de la vida, como si ambulara vuelto de espaldas, saliendo del camino y disminuyendo gradualmente hasta desaparecer en el horizonte.

Instintos de desconformidad habían creado el hábito de la fuga. Instabilidad perpetua, curiosidad, apetencia, duda y al final descontento, conciencia solitaria y escurridiza. No era él. Era la vida más fuerte que él mismo, moldeándole, plasmando su ser, de extrañas valencias.

$Y$ así Salterain demuestra el suplicio que padecen los humanos cuyas emociones discordantes les hacen acudir siempre a la fuga.

El año anterior al de la publicación de Fuga (1929), Salterain dió a sus lectores La casa grande. Pablo Granjean, inmigrante de Marsella y dueño de la casa grande, donde viven él y sus inquilinos, lleva vida solitaria como compositor. Después de la muerte de su mujer, su hija adoptiva, Laura, se fuga con su novio, vendedor clandestino de boletos del Hipódromo. Al fin, el viejo se casa con Antonia, simpática viuda que tiene casi tantos años como él. Temiendo no heredar la casa grande, Laura trata sin éxito de anular el casamiento. Antes del juicio Laura se da cuenta de la infidelidad de su marido, y se hace amante de Boneo, su abogado. Sin embargo, Boneo se decide a casarse con otra, y es brutalmente cínico en su última entrevista con Laura, que se suicida. A Granjean la consuelan los niños de Laura, enviados a su casa poco antes de la muerte de su madre. Sus proyectos siguen:

-Mira, Antonia -dijo-. Vamos a desocupar el taller, transformándolo, para que los niños puedan jugar. ¿No te parece? De todos modos, ya no se usa. 
Después, dispuso quitar el letrero de la calle, "Se hacen composturas con esmero y prontitud", y sonrió alegremente, pareciéndole la casa grande, más arreglada y hermosa que nunca. Era vieja, era humilde, eta buena...

No es difícil comprender por qué La casa grande sea más popular que Fuga. En aquélla la descripción psicológica de los personajes es secundaria a una trama desarrollada con rapidez, donde se sostiene la incertidumbre, hasta el final de la novela, de que Granjean no salga bien del juicio. La mayor parte de los médicōs tratan de probar que su padre ha sufrido cierta crisis nerviosa, con pérdida de la voluntad. Sin embargo, un compatriota de don Pablo, antiguo profesor de los otros médicos, los vence. La penetración psicológica es correcta sin muchos detalles, y completa sin agotamiento.

Indicios de la capacidad de Salterain para escribir novelas se encuentran en su tomo de cuentos Ansiedad (1922). Aquí se ve el interés del escritor por la gente. Aunque el tomo es corto - no tiene más que 131 páginas y consta de nada más que quince cuentosse presentan en él personajes de varias profesiones de la vida campestre y también de las ciudades del Uruguay. En todas estas descripciones Salterain da prueba de ser un observador correcto y completo de la naturaleza humana, y el lector tiene la impresión de que el autor conoció personalmente a los personajes y asistió a los hechos descritos. En todos los cuentos faltan las generalizaciones y los comentarios filosóficos que se encuentran en Fuga.

Ciertos cuentos habrán sido episodios observados por Salterain al cumplir las tareas de su carrera docente. En "La venganza de María" se encuentra entre los pasajeros de un tren expreso una maestra que hace el viaje diario a su escuela campestre. La presentación sigue :

Pero, hay entre estos seres discretos que el trabajo reúne a diario, una mujer aturdida, María, que gesticula ruidosamente y enseña geografía a gritos.

Maria es fea, María es intrigante, Maria es un ansia de ser feliz que todos los días se estrella contra la desgracia; María es una pobre enconada con la vida, que no logra satisfacerla. Inculta, frívola, no posee más que la vulgaridad; la vanidad enfática de un título, como el de graduados del aula, cubriendo muchas paredes 
hartas de pedantería. Nadie la quiere, nadie la ama, porque con ella se erige la antipatía que en balde lucha por ser simpática en los accesos de rabia silenciosa. Todo to desea hacer, todo lo pretende poder, enseñar, hablar, discernir; pero, nada quiere ni desea ardientemente tanto, como amar y ser amada. $Y$, por este empeño vive, camina, sufre.

Las advertencias repetidas del director acerca de las quejas de los padres de sus alumnos no valen nada, y María deja de ser maestra. Sin embargo, hace el viaje diariamente y sigue hablando de modo que todos los pasajeros la oigan. Un día, otra señora en el tren le pregunta:

- María, ¿es cierto que usted no está ya más en el colegio?

- Sí, es verdad - responde ella-. ¡Cómo quiere que una mujer como yo trabaje entre depravados! Figúrese usted que el otro día me llamó el Director, a mí sola, y pretendió seducirme, haciéndome toda clase de ofrecimientos. Claro está que yo me indigné -ifigúrese usted!- - y me fuí, renunciando mi puesto. De ese modo sacrifiqué yo mi porvenir, por ese canalla de hombre...

Dijo esto y complacida de sí misma, lanzó una mirada de odio a los profesores, que pareció un relámpago de triunfo...

Una señorita más simpática figura en "La clase de literatura". Es Alicia, quien sostiene correspondencia con su amiga Sara y le describe sus impresiones de la universidad. Sigue interesándose por la literatura, pero al fin se muere este interés al saber que su profesor no la quiere.

Patética es la viuda enferma y pobre de "Los trajecitos negros", que pasa las últimas horas de su vida haciendo secretamente unos trajecitos para sus niños.

Amalia de Otono demuestra la habilidad femenina de hacer decisiones rápidas. Por casualidad, se encuentra con Julio. Esto la hace recordar que sigue amando a Roberto, aunque se habian despedido muchos años antes. Al volver a su cuarto, vuelve a leer la última carta de Roberto, la destruye. Se da cuenta de que ella se parece a la naturaleza de otoño.

Despertóse al otro día, con el mismo pensamiento de afirmarse en el tiempo, de vivirlo antes del invierno. $Y$ por la tarde 
cenicienta, cuando el recuerdo de una carta no mordió ya su corazón, Amalia habló por teléfono y recibió después a Julio en la sala pálida de su casa. ¿Qué podría suceder?

-Dentro de un mes me caso - decía ella al concluir el día, en la plenitud de su voluntad, radiante de haber sepultado un inmenso desencanto.

La explicación de por qué Salterain no sigue escribiendo novelas y cuentos serán sus tareas de pedagogo. Lo que contribuye a su profesión es muy importante. Sin embargo, sus lectores siguen esperando que haga otras contribuciones a estos dos géneros literarios tan importantes.

VIRGIL A. WARREN, Carson-Nezman College. 
